\title{
İletişim Teknolojileri ve Değișen Empati Kavramı
}

\section{Communication Technologies and The Concept of Changing Empathy}

\section{İpek OKKAY ${ }^{[1]}$ Fatih $\mathbf{B A L}^{[2]}$}

Empati başkasının duygularını paylaşma yeteneğidir ve insanların gösterdiği en önemli özelliklerden biri sayılabilmektedir. Empati, paylaştığımız şeyleri keşfetmektir. Empati kurabilme yeteneği sevmemizi, öğrenmemizi, iletişim kurmamızı, iş birliği yapmamızı, gelişmiş ve başarılı bir toplumda yaşamamızı sağlamaktadır. Modern iletişim teknolojileri, günlük işlerimizi kolaylaştırmaktadır. İnsanlar kendi yaşamlarını ve topluluklarını iyileştirmek için gerekli değişiklikleri vurgulamak için empatiyi kullanırlar. Çağdaş kültürün diğer birçok öğesinde olduğu gibi sosyal ve mobil teknolojilerin hızlı bir şekilde benimsenmesi toplumun iletişim modellerini değiştirmiş ve özellikle dijital iletişim ile birlikte empati kavramı sarsıntıya uğramaya başlamıştır. Gelişen iletişim teknolojileri empati açığına sebep olabilmektedir. İletişim teknolojilerinin getirdiği tüm yenilik ve ilerlemeler topluma fayda sağlasa da fazla teknoloji kullanımı ilgisizlik, anti sosyallik gibi psikolojik sorunlara neden olabilmekte, iletişim kurma becerilerini zayıflatabilmektedir. Araștırmada veri toplama yolu olarak, "belge tarama- literatür tarama" yönteminden yararlanılmıștır. Bu doğrultuda iletişim teknolojilerinin empati kavramı üzerinde yaptığı değişiklikler alanyazında incelenmiştir. İletişim teknolojilerinin insanların empati kurabilme yetenekleri üzerinde negatif etkisi olduğunu, insanlar bireyselleştikçe empati açığının arttığı gözlemlenmiştir.

Anahtar Kelimeler: iletişim, teknoloji, empati, iletişim psikolojisi

Received Date:17 January 2021

Empathy is the ability to share someone else's emotions and can be considered one of the most important traits people show. Empathy is discovering what we share. The ability to empathize enables us to love, learn, communicate, collaborate, and live in a developed and successful society. Modern communication technologies make our daily work easier. People use empathy to highlight the changes needed to improve their own lives and communities. As in many other elements of contemporary culture, the rapid adoption of social and mobile technologies has changed the communication models of society and the concept of empathy has started to be shaken, especially with digital communication. Developing communication technologies may cause empathy gap. Although all the innovations and advances brought by communication technologies benefit society, the use of excessive technology can cause psychological problems such as apathy and anti-sociability, and weaken communication skills. The method of "document scanning - literature scanning" was used as a data collection method in the study. In this direction, the changes made by communication technologies on the concept of empathy were examined in the literature. It has been observed that communication technologies have a negative effect on people's ability to empathize, and empathy gap increases as people become more individualized.

Keywords: communication, technology, empathy, communication psychology https://doi.org/10.47793/hp.873320 


\section{GíRiş}

$\mathrm{E}$ mpatinin daha yüksek primatlara, yalnızca insanlara özgü olduğu düşünülmektedir (Langford, 2006). Empati her zaman medeniyetin kaderini şekillendirmiştir ve hatta geleceğimiz için belirleyici olacaktır. İnternet ve iletişim teknolojisi, ekonomiyi ve toplumu temelden değiștirmiştir (Rifkin, 2009). Gelişen iletişim teknolojilerinin toplumun her düzeyinde ekonomik, kültürel ve politik etkileri olmaktadır. İnsan eylemini ve insan zekasını makinelerden neyin ayırdığı sorusu genellikle şefkat, empati, insanlık gibi duygularla gündelik bir anlayışa dayalı olarak yanıtlanmaktadır.

Mobil, sosyal medya gibi iletişim teknolojilerinin kullanımı, bireylerin başkalarıyla ne zaman ve nasıl etkileşimde bulunduğunu değiştirmiştir. Düşünceleri, duyguları ve davranışları dijital kanallar aracılığıyla toplumun geri kalanıyla anında paylaşabilme özelliği geleneksel iletişim ile birlikte gelen empatik sosyal filtre yeteneğini ortadan kaldırmaya başlamıştır. Dahası, dijital iletişim yüz yüze ortamlarda yaşanan duygusal sinyallerin ve işaretlerin çoğundan yoksun, çoğu zaman kişisel olmayan etkileşimlere yol açmaktadır (Terry ve Cain, 2016).

\section{İletişim ve Teknoloji}

İletişim insanlar arasındaki gönderilen, değiş tokuş edilen, ortaklaşa kabul edilmiş, tanınmış semboller ve bunu kullananlar arasında ortak sahiplik olan 'kültür ve gelenekler' şeklinde tanımlandığında bile, iletişimin tanımı eksik kalmaktadır. İletişimde psikolojik etkenlerde önemli rol oynamaktadır. Ama bu psikolojik etkenleri sadece kişiliğe veya kişinin sosyal çevresine bağlamak yeterli olmamaktadır (Erdoğan, 1995). Özellikle günümüzde iletişim teknolojilerinin birey üzerindeki etkisi yadsınamaz hale gelmiştir. İletişim teknolojileri insanlar arasındaki bağı ve yakınlığı bozmanın yanı sıra kolaylaştırma potansiyeline sahip olmasından dolayı paradoksal bir yapıda olmaktadır (Przybylski ve Weinstein, 2012).

İletişim teknolojisi telekomünikasyonu, kullanıcıların uygulamalara erişmesini sağlayan yazılımı, bilgi iletme, işleme ve depolamayı, görsel-işitsel ortamını vurgulayan geniş kapsamlı bir terimdir. Radyo, televizyon, cep telefonları, bilgisayar ve ağ donanımları, uydu sistemleri ve benzerlerini kapsayan herhangi bir iletişim cihazının yanı sıra bunlarla birlikte video konferans gibi çeşitli hizmetleri ve cihazları içermektedir. Bilgileri elektronik olarak dijital bir biçimde depolayacak, işleyecek, iletecek veya alacak bilgisayar, e-posta, akıllı telefon, IPTV ve benzeri tüm ürünleri kapsamaktadır (Muhammad ve Garko, 2013).

İletişim teknolojilerindeki gelişmeler, bireylerin iletişim kurma şekilleri üzerinde ciddi bir etki yaratmıştır. İnsanların dijital olarak iletişim kurmasını sağlayan teknolojiler arttıkça yüz yüze iletişim / etkileşim azalmaya başlamıştır. Gün geçtikçe teknoloji insanların iletişim kurma biçiminin ayrılmaz bir parçası haline gelmiş ve giderek yüz yüze iletişimin yerini almaya başlamıştır (Drago, 2015).

Teknolojinin geniş kitlelerde uyandırdığı büyülenme, medya kavramının önemini vurgular niteliktedir. Teknoloji, düşünceler ve kavramlar düzeyinde etki etmese de anlam ilişkilerini ve algılama modellerini yavaş 
yavaş değişime uğratmaktadır (Maigret, 2014). İletişim teknolojileri iyi bir yaşam simülasyonu ile insanların bilinciyle olan bağlarını koparmaktadır. Kişilerin bireysel psikolojilerinde teknolojinin nasıl olup da bu denli önem kazandığı tam olarak çözülemese de teknolojiden etkilenmeye eğilimli kişiler genelde sevgiye yabancı insanlar olmaktadır. İçlerinde kalan tüm sevgi gücünü de teknolojik araçlara yöneltmektedirler (Adorno, 2003).

İletişim teknolojileri ile kurulan iletişim ve etkileşim diye adlandırılan her şey yapay ve gerçek yaşamdan uzak bir hal almaktadır. Bu sanal dünya da her șey iletişim kurmakta, ama hiçbir şey göz göze gelmemektedir (Baudrillard, 2013).

\section{İletişim Teknolojileri ve Değișen Empati Kavramı}

İnsana saygı, içtenlik ve dürüstlük ile birlikte hümanist psikolojinin üç temel dayanağından biri olan empati, karşıdaki kişinin duygu ve düşüncelerini kendininmiş gibi algılamak, nesnelliğini yitirmeden kendini onun yerine koymaktır (Bakırcıoğlu, 2012). Bireyin kişiliğini temelde toplum yanlısı davranma ve empati kurma becerisini etkilediği varsayılabilmektedir. Kendilik kavramının gelişiminin temsili ile desteklenen bağlanma teorisi temelinde, toplum yanlısı davranış ve empati duygusunun gelişimi önem taşımaktadır (Schuster, 2005).

Evrimsel bir perspektiften bakıldığında empatinin önemi bağ kurma, güvene dayalı ittifaklar oluşturma, çatışmayı çözme ve grup içi zihniyetin geliştirilmesiyle sonuçlanan nezaket ve iş birliği durumlarının ortaya çıkmasının rolü bulunmaktadır (De Waal, 2010). Empatide ilk önce başka bir kişinin yerinde olmanın nasıl bir his olduğunu hayal ederiz. Duygusal rezonans, bir olayı veya durumu hatırlama ve başka bir kişinin hissettiği gibi hissetme yeteneği olmaktadır. Empati anlam, amaç ve tatmin getirmektedir (Al-Shura, 2020).

Empati, başkalarının duygularını veya hislerini paylaşma ve anlama yeteneğini ifade etmektedir (Decety ve Lamm, 2006). Empatiyi deneyimlemek, otomatik bir erken duygusal bulaşma sistemi ve durumların öz düzenlemesine ve detaylandırılmasına izin veren daha yüksek düzeyde bir bilişsel sistem olmak üzere iki bileşenin bütünleşmesine dayanmaktadır (Decety ve Jackson, 2004). Duygusal empati, diğer insanların duygusal deneyimlerini paylaşma yeteneği olmaktadır (Ang ve Goh, 2010). Duygusal empati, bir kişinin başka bir kişinin hissettiğini ne ölçüde hissettiğidir ve bilişsel empati, kişinin başka bir kişinin düşüncelerini, niyetlerini ve duygularını ve empatik doğruluğu ne ölçüde etkilediğidir, perspektif alma, zihin teorisi olarak da adlandırılmaktadır (Batson, 2009). Blair (2005), duygusal empatinin başkalarının duygusal görünümlerine, yüz ve ses ifadelerine ve vücut hareketlerine tepki olduğunu öne sürmüştür. Salovey ve Mayer (1990), başkalarındaki sözel olmayan duygu algısı ve empatinin, duygusal zekanın yönleri olarak kabul edildiği, başkalarında duygularının değerlendirilmesi ve ifade edilmesi şeklinde iki kategori olduğunu öne sürmüştür. Burada duygu algısı, maksimum çaba ve tipik davranış empati olarak kavramsallaştırılmıştır. Mitchell ve Phillips (2015), duygusal algı ve bilişsel empati arasındaki kavramsal bağlantıları sıcak ve soğuk şeklinde ayırmıştır. Duygu algısı özellikle sosyal bilişin sıcak bir yönüdür çünkü duygusal bir süreçtir, bilişsel empati ise doğası gereği daha bilişsel olduğu için soğuk bir yönüdür. Duygu algısı genellikle daha düşük seviyeli bir bilişsel 
süreç olarak kabul edilir ve çevredeki yönleri tanımlamak olarak tanımlanır, bilişsel empati daha yüksek seviyeli bir bilişsel süreçtir, kişinin niyetleri ve inançları hakkında çıkarımlar yapmayı gerektirir.

Bilişsel empati, kişinin perspektif alma yeteneğine, nesnel bir gözlemci olarak kalırken başka bir kişinin deneyimini, duygularını veya zihinsel durumunu algılama veya anlama becerisine vurgu yapmaktadır (Teding ve Malouff, 2016). İster bir özellik ister bir durum olsun, gerçekten empatik bir tepki üretme yeteneği, sözel olmayan ipuçlarını anlama, bir başkasının duygusal durumuna duyarlı olma ve bir takım duygularını iletirken başka birinin perspektifini üstlenmeyi içeren karmaşı sosyo-bilişsel yeterlilikler gerektirir (Goldstein ve Michaels, 1985). Sosyal ve bilişsel işlevselliğin potansiyel bir ölçüsü olan empatinin, ortaya çıkması için gereken süreçlerin ayrılmaz bir parçası olarak, empatik tepkiye yardımcı olan görevleri yerine getirmek için gereken dikkati işlemeye atfedilebilmektedir (Dillard ve Hunter, 1989).

Kişilik, empatiyi etkileyen birçok faktörden biri olmaktadır (Hojat vd., 2005). Beş Faktör Modeli, yetişkinlerde kişiliği nevrotiklik, dışadönüklük, deneyime açıklık, uyumluluk ve vicdanlılık olmak üzere beş boyuttan oluşmaktadır (Muck vd., 2007). Vicdanlılık öz disiplin, sebat ve başarı için çaba gösterme gibi özellikleri içermektedir. Dışadönüklük sosyallik, olumlu etki ve enerjik davranış gibi özelliklerden oluşmaktadır. Uyumluluk özgeci, duygusal ve işbirlikçi davranışları ifade etmektedir. Nevrotiklik ilişkilerde kaygı, korku ve güvensizlik gibi davranışları içermektedir. Deneyime açılık, aktif hayal gücü ve estetik duyarlılık gibi özellikleri içermektedir. Açılık entelektüel merak ve iç görü içermekte, zeka ile harmanlanmaktadır (Caspi ve Shiner, 2005).

Empati, bilim adamlarının hala anlamaya çalıştığı, öykünme ve öğrenmeyi içeren bir zihin ağı teorisini içeren nörolojik bir sistem üzerinde çalışmaktadır. İletişim, empati yaratmanın merkezinde olmaktadır. İletişim teknolojileri, dilin başlangıcından yazmaya, telekomünikasyona, bilgi teknolojilerine kadar gelişmiştir (Manney, 2015). Dijital empati, kullanıcı deneyimini geliştirmek için teknolojiyi tasarlarken empatinin temel ilkelerinin (şefkat, biliş ve duygu) kullanılmasıdır. Friesem'e (2016) göre dijital empati, dijital medyayı stratejik olarak kullanırken, yansıtıcı ve sosyal olarak sorumlu olmanın bilişsel ve duygusal yeteneğidir. Dijital empatinin kökleri, bilişsel ve davranışsal sinirbilimciler tarafından başkalarının düşüncelerini ve duygularını paylaşma ve anlama kapasitesini açıklamak için kullanılan çok yönlü bir yapı olarak açıklanan bir insan davranışı olan empatiye dayanmaktadır (Decety ve Yoder, 2016). Empatinin nörolojik temeli, algı ve taklidin empatiyi kolaylaştırdığı ayna nöronlarda yatmaktadır (Carr vd., 2003). Empati, doğumdan bir iki gün sonra ortaya çıan en önemli insan duygularından biri olarak kabul edilmektedir (Sagi ve Hoffman, 1976). Son zamanlarda artan iletişim teknolojilerinin kullanımının empatiyi azalttığı düşünülmektedir (Twenge ve Foster, 2010).

Empati, insanların veya nesnelerin duygularımızın yansımaları olarak içimizde uyandırdığı sihirli bir duygudur (Spiro, 1992). Empati, duygu ve düşüncelerimizin yansımaları olarak içimizde kişi veya nesnelerin uyandırdığı duygudur. "Ben ve sen" "ben senim" ya da en azından "ben sen olabilirim" olduğunda aşikardır. Empati, filozofları ve sanat eleştirmenlerini, psikiyatristleri ve psikologları büyülemiştir (Book, 1988). Empatinin estetik ve kişisel olmak üzere iki yüzü bulunmaktadır. Freud'a (1955) göre empati, "başka bir 
zihinsel yaşama karşı herhangi bir tavır almamızı sağlayan bir mekanizmadır". Bireyler, başkalarıyla etkili bir şekilde iletişim kurabilmeli, empati kurabilmeli ve başkalarıyla uyumlu ilişkiler geliştirebilmelidir. Davis ve Kraus (1997), yaptıkları araștırmanın sonucunda empati tutumuna sahip bireylerin daha hoşgörülü ve başkalarına uyum sağlama eğilimli olduklarını tespit etmişlerdir. Başkalarıyla empati kurma becerisi, başarılı sosyal etkileşimlerde önemli faktörlerden biri olarak görülmektedir (Hetu, Taschereau ve Jackson, 2012). Yüz yüze iletişim büyük ölçüde teknolojiyle değişmeye başlamış, teknolojinin aşırı kullanımı kaygı uyandırır hale gelmiştir (Drago, 2015).

Alanyazında empatinin azalmakta olduğunu gösteren ve endişe uyandıran çalışmalar bulunmaktadır. Anderson ve Rainie (2012) tarafından yapılan araştırmada, \%87'sinin modern teknolojilerin kısa dikkat süreleriyle kolayca dikkati dağılan bir nesil yarattığı ve artan kullanımın teknoloji sabır kaybına ve derin düşünme eksikliğine yol açtığı bulunmuştur. Yapılan başka bir araştırmada katılımcıların \%71'i TV şovları, video oyunları, mesajlaşma ve sosyal ağlar gibi kitle iletişim teknolojilerinin dikkat aralıklarını bir şekilde veya çok etkilediğini düşündüklerini ortaya koymuş ve teknolojinin yüz yüze iletişim kurma becerilerini olumsuz etkilediğini göstermiş̦tir (Common Sense Media, 2012). Kirschner ve Karpinski (2010) yaptıkları araştırmada, sosyal ağ kullanımı sitelerinin dikkat süreleri üzerinde olumsuz bir etkisi olduğunu bulmuşlardır. Karşımızdaki kişi ile empati kurabilmemizde dikkat en önemli unsur olmaktadır. İnteraktif teknolojilerin dikkat üzerinde negatif etkileri olduğu yapılan araştırmalarda görülmektedir.

Konrath ve arkadaşları (2010), üniversite öğrencileri üzerinde yaptıkları araştırma neticesinde, empatinin 1979'dan beri düşüş gösterdiğini tespit etmişlerdir. 2009'da öğrencilerin yaklaşık \%75'inin 1979'da yapılan araştırmadaki öğrencilere göre kendilerini daha az empatik olarak değerlendirmiştir. En belirgin düşüş 2000 yılında meydana gelmiştir. Facebook ve cep telefonu kullanımı da dahil olmak üzere teknolojik ve medya tüketimindeki artışın, insanların dahil olduğu organizasyonların ve toplantıların sayısının yanı sıra ortalama aile yemekleri ve dost ziyaretlerinin sayısındaki düşüşe sebebiyet verdiği belirtilmiştir. Empatik duyguların zayıflamasının bir başka potansiyel açıklaması da empati ile negatif ilişkili olan narsisizm seviyelerinin 1980'lerden beri artmakta olmasıdır. Artan teknolojik kullanımı narsizmi tetiklemektedir (Twenge ve Foster, 2010). Bockarova (2016), tarafından yapılan araştırmada teknolojik kullanımdaki bir artışın, daha düşük empati ile ilişkili olduğu bulunmuştur.

İnsanların her yerde herkesle iletişim kurmasını sağlayarak, çok yakın veya dünyanın öbür ucundaki insanlarla sosyal etkileşimleri kolaylaştırsa da iletişim teknolojileri insan iletişimlerini kopartabilmektedir (Turkle, 2012). İnternet kullanım miktarının diğer insanlarla etkileşim kurma becerisiyle ters orantılı olduğu bulunmuştur (Engelberg ve Sjoberg, 2004). Buna göre bağımlılık düzeyinde internet kullanan kişiler genellikle sosyal yaşamlarını ihmal etmektedirler (Young, 1998). İnternet kullanıcıları arasındaki gerçek hayattaki sosyal etkileşimlerin giderek azalması, empatinin azalmasında etkili bir faktör olmaktadır (Melchers vd., 2015).

İnsanlar akıllı telefonlarını kullanmak için fiziksel olarak etkileşimde bulundukları kişileri görmezden gelebilmektedir. Phubbing adı verilen bu fenomen, günlük iletişimde normatif hale gelmeye başlamıştır 
(Chotpitayasunondh ve Douglas, 2016). Akıllı telefonların olumsuz etkisi, diğer insanlara kayıtsız kalmasına veya empati kaybına yol açarak ahlaki değerlerin zayıflamasına küstahlık, dolandırıcılık ve benzeri davranışlara neden olabilmektedir. Akıllı telefon kullanımı ile empati arasındaki ilişkinin, toplumda phubbing davranışı gibi yeni davranışlara yol açtığı ve sosyo kültürel değişiklikleri etkileyen faktörlerden biri olduğu düşünülmektedir (Latifa vd., 2019). Empati sadece akıllı telefon bağımlılığı davranışıyla yakından ilişkili değildir. Araştırmalar ayrıca öz kontrol, bağımlılık davranışlılarıyla da yakından ilişkili olduğunu ve ayrıca akıllı telefon kullanım problemleriyle de bağlantılı olduğunu göstermektedir (Malouf vd., 2013). Karşılıklı ilişkiler, bir kişinin olumlu sonuçları olan sosyal eylemlere tepki verdiğinde veya olumsuz sonuçlarla sonuçlanan eylemlerle karşıllk verdiğinde ortaya çlkmaktadır (Pelaprat ve Brown, 2012). Bununla birlikte toplum her zaman yeni sosyal normlarda değişiklikler yaşar ve insanlar bu normları hızla benimseme eğilimindedir (Sunstein, 1996). Normlar ayrıca gözlemlenebilir davranıştan kaynaklanmaktadır (Miller, 1996). Buna ek olarak cinsiyetin çevrimiçi aktiviteleri tercih etme (Ha ve Hwang, 2014) cep telefonu bağımlılığı (Jeong vd., 2016), internet bağımlılı̆̆ (Khan vd., 2017), öz kontrol (Nakhaie vd., 2000) ve iletişim görgü kuralları (Forgays vd., 2014) gibi akıllı telefonla ilgili birçok davranışı etkilemede rol oynadığı bulunmuştur.

Sosyal ağları kullanmak duygusal destek, kendini ifade etme ve topluluk oluşturma gibi önemli faydalara sahip olsa da olumsuz etkileri de dikkat çekici olmaktadır (Esfahani vd., 2019). Sosyal medyanın aşırı ve sorunlu kullanımı, akıllı telefonların aşırı ve sorunlu kullanımı ve birden fazla cihazın aynı anada kullanımı (multitasking) ile ilişkili olmaktadır (Lachmann, 2018). Akıllı telefonun aşırı kullanımının sosyal etkileşimlerdeki sorunlar, sosyal olarak izole olma, anksiyete, depresyon ve stres gibi sağlık sorunları ve çeşitli olumsuz sonuçlarla ilişkili olduğu bulunmuştur (Griffiths ve Kuss, 2017). Sosyal medyanın bir parçası olan sosyal ağlar, kültürel ve sosyal ihtiyaçları karşılamanın yanı sıra bireylerin bilgisayarlar veya akıllı telefonlar aracılığıyla sosyal aktiviteler gerçekleștirmelerine, bu sanal topluluklardaki aktivitelerini takip etmelerine ve diğer insanlarla etkileşimde bulunmalarına olanak tanımaktadır (Tunc ve Akbay, 2019). Sosyal medya kullanımı küresel olarak katlanarak artmış Facebook, Twitter ve Instagram gibi sosyal medya ağlarının her yerde mevcut olması bazı kullanıcıların bağımlı hale gelmesine sebebiyet verebilmektedir. Dışadönüklük ve nevrotiklik gibi kişilik özellikleri, kaybetme korkusu (fomo) ve cep telefonu olmaması fobisi (nomofobi) gibi psikolojik durumlar sosyal ağların sorunlu ve bağımlılık yaratan kullanımıyla ilgili olan faktörlerdir (Griffiths ve Kuss, 2017). Bazı araştırmacılar sosyal etkileșimler ve internet bağımlılığı ile ilişkili araştırmalarda sosyal becerilerin eksikliklerini vurgulamaktadır (Wichstrom vd., 2018). Sosyal etkileşimlerde en hayati insan yeteneklerinden biri kişiler arası ilişkilerde çok önemli bir rol oynayan empati olmaktadır. Araştırmalara göre internet bağımlısı olanların empati eksikliği bulunmaktadır (Jiao vd., 2017). Dalvi ve arkadaşları (2020) yaptıkları araştırmada, empati ve sosyal medya bağımlılığı arasında ilişki bulmuştur. Conmy (2010) yaptığı araştırmada, dijital oyun bağımlılarının özellikle şiddet içeren oyunları tercih eden katılımcılar ve bir kaçış biçimi olarak dijital oyunları kullanan katılımcıların daha zayıf sosyal becerilere ve daha düşük empati seviyelerine sahip olduğunu bulmuştur. Yapılan araştırmalar internet kullanım bozukluğu, empati ve yaşam doyumu arasındaki ilişkiye dair kanıtları ortaya koymaktadır (Lachmann, 2018). 
Empati yaratmanın merkezinde iletişim bulunmaktadır (Stiff vd.,1988). İletişim teknolojilerindeki değişiklikler, empati eksikliğine yol açan önemli faktörlerdendir (Konrath vd., 2011). Dijital iletişim, geleneksel yüz yüze iletişimdeki empatik sosyal filtreden yoksun bulunmaktadır (Terry ve Cain, 2016). Sosyal medya kullanıcılarının röntgenci eğilimleri (Komito, 2011), genel kendini geliştirme ve dikkat çekme davranışları (Seidman, 2013), çevrimiçi arkadaşlar (Grabowicz vd., 2012) ve tüketilen herhangi bir bilgiye seçici bir şekilde dikkat etme yeteneği teknoloji ile birlikte hayatımıza giren empati açıklarından bazıları olmaktadır.

Dijital iletişim teknolojisinin hızla benimsenmesi nedeniyle iletişim giderek daha çevrimiçi hale geldikçe, toplumun iletişim kalıpları hem olumlu hem de olumsuz olarak hızla değişmiştir. Teknoloji kullanımı, insan etkileşimlerini, insanların düşüncelerini, hislerini ve davranışlarını dijital kanallar üzerinden birkaç saniye içinde anında paylaşabildikleri dijital konuşmalara dönüştürmüştür. Suler (2004), dijital sohbetlerin büyük ölçüde "çevrimiçi disinhibisyon etkisi" nedeniyle empatinin uygun ifadesini tehdit ettiğini belirtmekte, çevrimiçi disinhibisyon etkisini "insanların siber uzayda normalde yüz yüze söylemeyecekleri ve yapmayacakları şeyler söyleyip yapmaları" eğilimi olarak tanımlamaktadır. İnsanlar ne kadar kolay ilişki kurabiliyorsa aslında o kadar çok ilişkisizleşmekte, sevememekte, asosyalleşmekte ya da narsistleşmektedir (Claussen, 2012). Rushkoff (2013) dijital cihazlara daha bağımlı hale geldiğimizi belirtmektedir. Dijital olan her şeyle sürekli etkileşimimiz, bizi duygusal ve bilişsel olarak etkileyen şekillerde bizi insan etkileşiminden uzaklaştırmaktadır (Carr, 2010).

\section{SONUÇ}

Dünya küçüldükçe ve daha bağlantılı hale geldikçe, empatinin rolü her zamankinden daha büyük ve daha önemli hale gelmektedir. Empatinin olmadığı yerde çatışma çoğalır. Bununla birlikte interaktif teknolojilere bağlılığımız arttıkça küresel empatinin de azalmaya başladığı görülmektedir (Manney, 2015).

Küresel Risk Raporu (2019) teknolojinin, yalnızlığın ve sosyal izolasyonun başlıca nedeni olarak gösterildiğini belirtmektedir. Toplumsal, teknolojik ve işle ilgili üç alandaki karmaşık dönüşümler, öfkenin arttığı ve empatinin azalmakta olduğu, giderek daha endişeli, mutsuz ve yalnız bir dünya yaratmaktadır. Yaygın dijital teknoloji, işyeri ile ev arasındaki sınırı da bulanıklaştırmıştır. İnsan ve teknoloji arasındaki çizgi gün geçtikçe bulanıklaşmaya başlamış, yalnızlık ve kutuplaşmalar artmaya başlamış, buna bağlı olarak empati açığında artış olmuştur. Birçok toplumda aile bağları bozulmaya başlamıştır. Çevrimiçi bağlantıların empatik olabilmesine karşın, araştırmalar empati derecesinin gerçek dünya etkileşimlerinden altı kat daha zayıf olduğunu öne sürmektedir.

İnsanlar zihinsel ve teknolojik olarak geliştikçe kendi hareketlerinin sorumluluğunu yükleyebileceği günah keçilerini daha zekice yaratmakta ve kolay olanı seçmektedirler (Baudrillard, 2014).

İnsanlar başkalarına çevrimiçi olarak empatik tepkiler gösterebilirler, ancak aynı zamanda teknoloji temelli iletişim yaygınlaştığından beri özellikle yeni gelen nesillerde empati azaldığı da bir gerçektir. Yüz yüze zamanın çevrimiçi aktivitelerle yer değiştirmesinin empatik becerileri olumsuz yönde etkilemesi kaçınılmaz 
olmaktadır (Carrier vd., 2015). Araştırmalar, yüz yüze iletişimden uzaklaşmanın gençlerin sosyal-duygusal becerilerinde bir düşüşe neden olduğunu göstermiş ve teknoloji ile büyüyen nesillerin daha az empatik hale geldiğini göstermektedir (Konrath vd., 2011). İletişim teknolojileri ebeveynleri bile empatik olarak çocuklarının duygularını anlayabilecek gerekli fiziki donanımlardan yoksun hale getirmeye bașlamıștır (Postman, 1995).

İletişim teknolojilerinin gücü hem empatiyi yok edecek hem de yaratabilecek yapıdadır. Toplumsal olarak bir bütün olduğumuzu hatırlayıp insanların hayatını önemsersek teknoloji empatiyi yok edemez. Bu noktada gelişim sürecimizdeki sosyal çevremiz; ailemiz, eğitim aldığımız kurum ve arkadaşlarımız, empati kurabilen bir birey haline gelmemizde temel yapı taşları olmaktadır. İletişim teknolojilerinin bireysel yapısı, sosyal iletişimimizi her geçen gün zayıflatmakta bizi bireysel olmaya yöneltmektedir. Bireyselleşme arttıkça insanların empati kurabilme yetenekleri azalmaya başlamıştır.

\section{KAYNAKÇA}

Adorno, T. W. (2003). Auschwitz sonrasında eğitim. Adorno: Kitle, melankoli, felsefe. Cogito, 36, 236-243.

Al-Shura, A. N. (2020). Medical empathy, pharmacological systems, and treatment strategies in integrative cardiovascular chinese medicine. Academic Press.

Anderson, J. Q. ve Rainie, L. (2012). Millennials will benefit and suffer due to their hyperconnected lives. Pew Research Center.

Batson, C. D. (2009). These things called empathy: Eight related but distinct phenomena. J. Decety ve W. Ickes (Eds.), The social neuroscience of empathy (pp. 3-16). MIT Press.

Bockarova, M. (2016). The intersection between technology, mind-wandering, and empathy. S. Y. Tettegah \& D. L. Espelage (Eds.), Emotions, technology, and behaviors (pp. 47-62). Elsevier.

Bakırcıoğlu, R. (2012). Ansiklopedik eğitim ve psikoloji sözlüğü. Anı Yayıncllık.

Baudrillard, J. (2013). Amerika. Ayrıntı Yayınları.

Baudrillard, J. (2014). Cool Anılar I-II 1980-1990. Ayrıntı Yayınları.

Blair, R. J. R. (2005). Responding to the emotions of others: Dissociating forms of empathy through the study of typical and psychiatric populations. Consciousness and Cognition, 14, 698-718.

Book H. E. (1988). Empathy: misconceptions and misuses in psychotherapy. Am J Psychiatry. 145, 420-424.

Carr, N. (2010). The shallows: How the Internet is changing the way we think, read and remember. W.W. Norton \& Company.

Carr, L., Iacoboni, M., Dubeau, M. C., Mazziotta, J. C. ve Lenzi G. L. (2003). Neural mechanisms of empathy in humans: a relay from neural systems for imitation to limbic areas. Proceedings of the National Academy of Sciences of the United States of America, 100(9), 5497-5502. 
Carrier, L. M., Spradlin, A., Bunce, J. P. ve Rosen, L. D. (2015). Virtual empathy: Positive and negative impacts of going online upon empathy in young adults. Computers in Human Behavior, 52, 39-48.

Caspi, A., Roberts, B. W. ve Shiner, R. (2005). Personality development: Stability and change. Ann Rev Psychol, 56:453-484.

Chotpitayasunondh, V. ve Douglas, K. M. (2016). How phubbing becomes the norm: The antecedents and consequences of snubbing via smartphone. Computers in Human Behavior, 63, 9-18.

Claussen, D. (2012). Son deha: Theodor W. Adorno. Yapı Kredi Yayınları.

Common Sense Media (2012). Children, teens, and entertainment media: The ew from the classroom. A Common Sense Research Study.

Conmy, E. (2010). Video game addiction and its possible negative effects on social skills and empathy in adolescents. Dublin Business School.

Dalvi, M.E, Niknafs, A., Alaedini, Z., Barati Ahmadabadi, H., Kuss, D. J. ve Ramayah, T. (2020). Social media addiction and empathy: Moderating impact of personality traits among high school students. Telematics and Informatics, 57, 101516.

Davis, M. H. ve Kraus, L. A. (1997). Personality and empathic accuracy. W. J. Ickes (Eds.), Empathic accuracy (pp. 144-168). Guilford Press.

Decety, J. ve Jackson, P. L. (2004). The functional architecture of human empathy. Behav. Cogn. Neurosci. Rev, 3, 71-100.

Decety, J. ve Lamm, C. (2006). Human empathy through the lens of social neuroscience. Scientific World Journal, 6, 1146-1163.

Decety, J. ve Yoder, K. J. (2016). Empathy and motivation for justice: Cognitive empathy and concern, but not emotional empathy, predict sensitivity to injustice for others. Social Neuroscience, 11(1), 1-14.

De Waal, F. (2010). The age of empathy: Nature's lessons for a kinder society. Random House LLC.

Dillard, J. P. ve Hunter, J. E. (1989). On the use and interpretation of the emotional empathy scale, the selfconsciousness scales, and the self-monitoring scale. Communication Research,16(1), 104-129.

Drago, E. (2015). The effect of technology on face-to-face communication. The Elon Journal of Undergraduate Research in Communications, 6(1), 13-19.

Engelberg, E. ve Sjoberg, L. (2004). Internet use, social skills, and adjustment. Cyberpsychol. Behav, 7, 41-47.

Erdoğan, İ. (1995). Dünyanın çarpık düzeni uluslararası iletişim. Kaynak Yayınları.

Esfahani, M. D., Niknafs, A, Kuss, D., Nilashi, M. \& Afrough, S. (2019). Social media addiction: Applying the DEMATEL approach. Telematics and Informatics, 43, 101250. 
Freud, S. (1955). Group psychology and the analysis of the ego. J. Strachey (Eds.), The complete works of sigmund Freud. Hogarth Press.

Friesem, Y. (2016). Empathy for the digital age. S. Y. Tettegah \& D.L. Espelage (Eds.), Emotions, technology, and behaviors (pp. 21-45). Elsevier.

Goldstein, A. P. ve Michaels, G. Y. (1985). Empathy: Development, training, and consequences. L. Erlbaum Associates.

Grabowicz, P. A., Ramasco, J. J., Moro, E., Pujol, J. M. ve Eguiluz, V. M. (2012). Social features of online networks: The strength of intermediary ties in online social media. PloS One, 7(1), e29358.

Griffiths, M. ve Kuss, D. (2017). Adolescent social media addiction. Education and Health, 35(3), 49-52.

Ha, Y. ve Hwang, W. J. (2014). Gender differences in internet addiction associated with psychological health indicators among adolescents using a national web-based survey. Journal of Mental Health and Addiction, 12(5), 660e669.

Forgays, D. K., Hyman, I. ve Schreiber, J. (2014). Textingeverywhere for everything: gender and age differences in cell phone etiquette and use. Computers in Human Behavior, 31,314-321.

Hetu, S., Taschereau-Dumouchel, V. ve Jackson, P. L. (2012). Stimulating the brain to study social interactions and empathy. Brain Stimul, 5, 95-102.

Hojat, M., Zuckerman, M., Magee, M., Mangione, S., Nasca, T., Vergare, M. ve Gonnella, J. (2005). Empathy in medical students as related to specialty interest, personality, and perceptions of mother and father. Pers Individual Differences, 39, 1205-1215.

Jiao, C., Wang, T., Peng, X. ve Cui, F. (2017). Impaired empathy processing in individuals with internet addiction disorder: An event-related potential study. Frontiers in Human Neuroscience, 11.https //doi.org/10.3389/fnhum.2017.00498.

Jeong, S. H., Kim, H., Yum, J. Y. ve Hwang, Y. (2016). What type of content are smartphone users addicted to? SNS vs. games. Computers in Human Behavior, 54, 10-17.

Khan, M. A., Shabbir, F. ve Rajput, T. A. (2017). Effect of gender and physical activity on internet addiction in medical students. Pakistan Journal of Medical Sciences, 33(1).https //doi.org/10.12669/pjms.331.11222

Kirschner, P. A. ve Karpinski, A. C. (2010). Facebook and academic performance. Computers in Human Behavior, 26(6), 1237-1245.

Konrath, S. H., O'Brien, E. H. ve Hsing, C. (2011). Changes in dispositional empathy in American college students over time: a meta-analysis. Personality and Social Psychology Review,15(2), 180-198. 
Komito, L. (2011). Social media and migration: Virtual community 2.0. Journal of the American Society for Information Science and Technology, 62(6), 1075-1086.

Lachmann, B., Sindermann, C., Sariyska, R. Y., Luo, R., Melchers, M. C., Becker, B., Cooper A.J. ve Montag, C. (2018). The role of empathy and life satisfaction in internet and smartphone use disorder. Frontiers in Psychology, 9(398).

Langford, D. J. (2006). Social modulation of pain as evidence for empathy in mice. Science, 312(5782), 1967-1970.

Latifa, R., Mumtaz, E. F. ve Subchi, I. (2019 January). Psychological explanation of phubbing behavior: Smartphone addiction, emphaty and self control. 7th International Conference on Cyber and IT Service Management (CITSM), Jakarta, Indonesia.

Malouf, E. T., Schaefer, K. E., Witt, E. A., Moore, K. E., Stuewig, J. ve Tangney, J. P. (2013). The brief self-control scale predicts jail inmates' recidivism, substance dependence, and post-release adjustment. Personality \& Social Psychology Bulletin, 40(3), 334-347.

Manney, P. J. (2008). Empathy in the Time of Technology: How Storytelling is the Key to Empathy. Institute for Ethics and Emerging Technologies, 19(1), 51-61.

Maigret, E. (2014). Medya ve iletişim sosyolojisi. İletişim Yayınları.

Melchers, M., Li, M., Chen, Y., Zhang, W. ve Montag, C. (2015). Low empathy is associated with problematic use of the internet: Empirical evidence from China and Germany. Asian J. Psychiatr. 17, 56-60.

Miller, D. T. ve Prentice, D. A. (1996). The construction of social norms and standards. E. T. Higgins \& A. W. Kruglanski (Eds.), Social psychology: Handbook of basic principles (pp. 799-829). Guilford Press.

Mitchell, R.L. ve Phillips, L.H. (2015). The overlapping relationship between emotion perception and theory of mind. Neuropsychologia, 70, 1-10.

Muck, P., Hell, B. ve Gosling S. 2007. Construct validation of a short five-factor model instrument: A self-peer study on the German adaptation of the Ten-Item Personality Inventory (TIPI-G). Eur J Psychol Assess, 23(3), 166-175.

Muhammad, M. ve Garko A. B. (2013). Information and communication technologies (ICT): A tool for good governance. M. Muhammad, A. B. Garko \& M. T. Yakasai (Eds.), Advances in information and communication technologies. Ahmadu Bello University Press Limited.

Nakhaie, M. R., Silverman, R. A. ve LaGrange, T. C. (2000). Selfcontrol and social control: an examination of gender, ethnicity, class and delinquency. Canadian Journal of Sociology/Cahiers Canadiens De Sociologie, 35-59. http://dx.doi.org/10.2307/3341910.

Pelaprat, E. ve Brown, B. (2012). Reciprocity: understanding online social relations. First Monday, 17(10). http://dx.doi.org/10.5210/fm.v17i10.3324. 
Postman, N. (1995). Çocukluğun yok oluşu. İmge Kitabevi.

Przybylski, A. K. ve Weinstein, N. (2012). Can you connect with me now? How the presence of mobile communication technology influences face-to-face conversation quality. Journal of Social and Personal Relationships, 30(3), 237-246.

Rifkin, J. (2009). Die empathische zivilisation wege zu einem globalen bewusstsein. Campus Verlag.

Rushkoff, D. (2013). Present shock: When everything happens now. Penguin.

Salovey, P. ve Mayer, J. D. (1990). Emotional intelligence. Imagination, Cognition and Personality, 9, 185-211.

Sagi, A. ve Hoffman, M.L. (1976). Empathic distress in the newborn. Developmental Psychology, 12(2), 175.

Seidman, G. (2013). Self-presentation and belonging on Facebook: How personality influences social media use and motivations. Personality and Individual Differences, 54(3), 402-407.

Schuster, N.(2005). Die bedeutung der frühkindlichen bindungserfahrungen für die entwicklung von prosozialem handeln und empathie. Diplomarbeiten Agentur.

Spiro, H. (1992). What is empathy and can it be taught? Annals of Internal Medicine, 116(10), 843.

Stiff, J. B., Dillard, J. P., Somera, L., Kim, H. ve Sleight, C. (1988). Empathy, communication, and prosocial behavior. Communication Monographs, 55(2), 198-213.

Suler, J. (2004). The online disinhibition effect. Cyberpsychology \& Behavior, 7(3), 321-326.

Sunstein, C. R. (1996). Social norms and social roles. Columbia Law Review, 903-968. http://dx.doi.org/10.2307/1123430.

Teding E. B. ve Malouff, J. M. (2016). The efficacy of empathy training: A meta-analysis of randomized controlled trails. Journal of Counseling Psychology, 63, 32e41.

Terry, C. ve Cain, J. (2016). The emerging issue of digital empathy. Am J Pharm Educ. 80(4), 58.

Tunc, A. A. ve Akbay, S. E. (2019). Smartphone addiction, fear of missing out, and perceived competence as predictors of social media addiction of adolescents. European Journal of Educational Research, 8(2), 559566.

Turkle, S. (2012). Alone together: Why we expect more from technology and less from each other. Basic Books.

Twenge, J. M. ve Foster, J. D. (2010). Birth cohort increases in narcissistic personality traits among American college students, 1982-2009. Social Psychological and Personality Science, 1(1), 99-106.

Wichstrom, L., Stenseng, F., Belsky, J., von Soest, T. ve Hygen, B. W. (2018). Symptoms of internet gaming disorder in youth: Predictors and comorbidity. Journal of Abnormal Child Psychology, 47, 71-83.

WEF (2019) The global risks report. World Economic Forum. 
Young, K. S. (1998). Caught in the net: How to recognize the signs of internet addiction and a winning strategy for recovery. Wiley.

\section{EXTENDED ABSTRACT}

Empathy is the ability to share someone else's emotions and can be considered one of the most important traits people show. Empathy is discovering what we share. The ability to empathize enables us to love, learn, communicate, collaborate, and live in a developed and successful society. Modern communication technologies make our daily work easier. People use empathy to highlight the changes needed to improve their own lives and communities. As in many other elements of contemporary culture, the rapid adoption of social and mobile technologies has changed the communication models of society and the concept of empathy has started to be shaken, especially with digital communication. Developing communication technologies can cause empathy gap. Although all the innovations and advances brought by communication technologies benefit society, the use of excessive technology can cause psychological problems such as apathy and anti-sociability, and weaken communication skills. The method of "document scanning - literature scanning" was used as a data collection method in the study. In this direction, the changes made by communication technologies on the concept of empathy were examined in the literature.

Developing communication technologies have economic, cultural and political effects at all levels of society. The question of what separates human action and human intelligence from machines is usually answered based on a daily understanding with feelings such as compassion, empathy, and humanity. The use of communication technologies such as mobile and social media has changed when and how individuals interact with others. The ability to instantly share thoughts, feelings and behaviors with the rest of the society through digital channels has begun to remove the empathic social filtering ability that comes with traditional communication.

The Global Risk Report (2019) states that technology is cited as the main cause of loneliness and social isolation. Complex transformations in the three social, technological, and work-related areas create an increasingly anxious, unhappy and lonely world where anger is on the rise and empathy decreases. Pervasive digital technology has blurred the boundary between workplace and home. The line between human and technology has begun to blur day by day, loneliness and polarization have started to increase, and the empathy gap has increased accordingly. Family ties have begun to deteriorate in many societies. While online connections can be empathetic, research suggests the degree of empathy is six times weaker than real-world interactions.

The power of communication technologies is capable of both destroying and creating empathy. If we remember that we are socially united and care about people's lives, technology cannot destroy empathy. At this point, our social environment in our development process; Our family, the institutions we receive education and our friends are the basic building blocks for us to become an individual who can empathize. The individual 
structure of communication technologies weakens our social communication day by day and drives us to be individual. As individualization increases, people's ability to empathize has started to decrease. It has been observed that communication technologies have a negative effect on people's ability to empathize, and empathy gap increases as people become more individualized. 